Research Article

www.jestr.org

\title{
Properties of Starch/Carrageenan Blend Biocomposite with Nanoclay Reinforcement
}

\author{
Heru Suryanto ${ }^{1, *}$, Lalang Patrya Mahera ${ }^{1}$, Febri Adi Kharismawan' ${ }^{1}$, Septian Maulana \\ Saragih $^{1}$, Solichin Solichin ${ }^{1}$ and Uun Yanuhar ${ }^{2}$
}

${ }^{1}$ Department of Mechanical Engineering, Faculty of Engineering, Universitas Negeri Malang, Indonesia

${ }^{2}$ Department of Water Resource Management, Faculty of Fisheries and Marine Sciences, Brawijaya University, Indonesia

Received 26 May 2019; Accepted 10 September 2019

\begin{abstract}
The highly synthetic plastic waste makes worrisome problems for the biosphere, so the use of bioplastic was applied for reducing this problem. Biocomposite based cassava starch-carrageenan blend with nanoclay reinforcement has great potential to increase their properties. The research objective was to evaluate the biocomposite properties in the presence of nanoclay added to starch/carrageenan blend matrix composite. The method was an experiment research using addition various nanoclay content as much as $2.5 \%, 5.0 \%, 7.5 \%$, and $10.0 \%(\mathrm{wt} / \mathrm{wt})$ into starch/carrageenan blend matrix. The procedures include a biocomposite synthesis using the casting methods and characterized of biocomposite properties using XRD, FTIR, SEM, and TGA. The mechanical strength was measured on a tensile strength tester. The results show that the nanoclay addition into starch/carrageenan matrix affects the structure, tensile strength, and thermal stability. This result shows that the addition of nanoclay into starch/carrageenan based matrix affects the mechanical properties, thermal stability through structural change. The variations of nanoclay content in biocomposite of $0,2.5,5.0,7.5$, and $10 \%$ results in a tensile strength of $580,636,760,483$, and $531 \mathrm{kPa}$ and elastic modulus of 1621, 1681, 1745, 1133, $1176 \mathrm{kPa}$, respectively.
\end{abstract}

Keywords: Biocomposite; mechanical properties; nanoclay; starch/carrageenan blend

\section{Introduction}

Plastics are a polymer that widely applied in materials for the packaging because of their advantages such as chemically resistant, lightweight, and inexpensive [1]. Some limitations of plastics include the release of toxic chemicals in the manufacturing process and also during the incineration process resulting in pollution, which affects human health [2]. The most important issue of using synthetic plastics-based packaging is the post-consumer waste as the most significant contributor to plastic waste in the landfill. The amount of this waste has to be increased from $\sim 40 \%$ to $63 \%$ by 2022 [3]. Besides, it has estimated that the plastic materials about less than $14 \%$ can recycle, and some type of plastics are difficult to reuse [4]. They are hard to break down and difficult to decompose at a short time and to completely degrade in landfills for approximately more than 50 years [5]. The synthetic plastic consumption of worldwide reached 322 million tons in 2015, increase to 248 million metric tons in 2017 [6]. Indonesia is a critical country in which to tackle waste. They produce a total plastic waste of about 80,235 tons per day [7]. The highly plastic waste cause serious problems for biosphere because of non-renewable and not degradable [8].

A feasible way to solve the synthetic polymer waste problem is developing the biodegradable polymer that is easily decomposed in the landfill. Starch, biomaterials that are renewable, abundant, inexpensive, biodegradable, and

*E-mail address: heru.suryanto.ft@um.ac.id

ISSN: $1791-2377$ @ 2019 School of Science, IHU. All rights reserved.

doi:10.25103/jestr.125.14 biocompatible, was extracted from tubers plants such as potatoes, yams, and cassava [9]. The biodegradable polymers usually contain ingredients such as polysaccharides, proteins, and lipids, that degraded more readily than the non-renewable polymer or the synthetic polymers. These polymers have applied in food and biomaterial products or as packaging material due to its preservative capabilities and degradability, which are of great benefit to the health and environment [10].

Carrageenan is a common name for a family of viscosifying polysaccharide, which is gained by extraction from seaweeds specifically from the family of Rhodophyceae [11]. Kappa-carrageenan has excellent properties to form membranes and gels that exhibit good mechanical properties [12]. The new bio-based polymer has developed for making biodegradable packaging as an effort to extend the food quality, shelf life of food, and to reduce the waste from plastic packaging. Because of the deliberate contact with the food environment, edible films, the food itself, and food coating, so, the biopolymer is excellent alternatives for packaging of traditional food.

The blend of starch polysaccharides with gelatin, polylactic acid, and polycaprolactone have been reported [13]. Polymer blend provides a synergistic effect on their physicochemistry properties. However, the wide application of starch-based bioplastics has been limited due to their brittleness, poor mechanical properties, moisture sensitivity [14], and poor processability in conventional industrial equipment [15]. The attractive approaches have been developed for overcoming the poor mechanical properties of starch was produce starch composite reinforced with 
reinforcement such as natural fibers [15], Zinc nanoparticle [16], chitosan [17], and nanoclay [18]. More recently, most of the studies have been a focus on layered silicates of nanoclay, as the phase reinforcement due to versatility and large availability as well as the wide interface surface area triggering the strong interaction to the polymer matrix. Therefore, the effect of nanoclay addition into starch/carrageenan-based biocomposite for the packaging needs to be investigated. The study aims to examine the impact of nanoclay added into starch/carrageenan matrix on the properties of biocomposite.

\section{Experimental Methods}

\subsection{Material}

Kappa-carrageenan and starch were in technical grade purchase from CV. Makmur Sejati, Malang, Indonesia. A reinforcement of biocomposite was surface modified nanoclay, contains trimethyl stearyl ammonium range 25-30 $\%$ wt, supplied by the Sigma Aldrich, Singapore.

\subsection{Biocomposite Synthesis}

Biocomposite was prepared using the casting methods. 98.5 $\mathrm{ml}$ of distilled water was added with $1.5 \%(\mathrm{v} / \mathrm{v})$ glycerols in beaker glass while stirring for $5 \mathrm{~min}$. at $900 \mathrm{rpm}$. Each treatment contains $2.5 \%, 5 \%, 7.5 \%$, and $10 \%(\mathrm{wt} / \mathrm{wt})$ of nanoclay. It was added into the solution then homogenized through sonication process $(300 \mathrm{~W}, 20 \mathrm{kHz}$ using the Ultrasonic Homogenizer (KG-MT-UPDHM-3N, KGC Indonesia)) for $60 \mathrm{~min}$. [19]. 5.0\% (wt/v) cassava starch was dissolved in the homogenized solution while stirrer for 30 min at $80^{\circ} \mathrm{C}$. $1.0 \%(\mathrm{wt} / \mathrm{v})$ carrageenan was added into the solution until show gelation then poured into the mold and put it into an oven with holding the temperature of $70{ }^{\circ} \mathrm{C}$ for four hours until dry. Dried biocomposite was kept in the dry box.

\subsection{Mechanical properties analysis}

The strength and elastic modulus as mechanical properties representation of biocomposite were measured using a tensile test machine (Techno Lab., Indonesia; max. load capacity of $50 \mathrm{~N}$ ) according to ASTM D882 standard. The dimension of specimens was $60 \times 5 \times 0.5 \mathrm{~mm}^{3}$. The specimens were clamped in the grips with the spacing of 50 $\mathrm{mm}$ then pulled by $0.025 \mathrm{~mm} \cdot \mathrm{s}^{-1}$ until breakage. Each treatment was tested for ten samples.

\subsection{XRD analysis}

The structure of biocomposite was observed by XRD equipment (PanAnalytical X-Pert Pro). Scanning was run at $30 \mathrm{~mA}$ and $40 \mathrm{kV}$ with $\mathrm{CuK} \alpha$ radiation $(\lambda=1.540598 \AA)$ in the ambient temperature with a rate of $0.02^{\circ}$ per step from 10 to $80^{\circ}$. Biocomposite film with a thickness of $200 \mu \mathrm{m}$ was cut into the area of $10 \times 10 \mathrm{~mm}^{2}$ used for XRD analysis.

\subsection{FTIR analysis}

FTIR (Fourrier Transform Inftra Red) spectra were recorded in the FTIR Spectrometer (IRPrestige-21, Shimadzu Co., Japan). IR spectrum was collected in wave number from $4000 \mathrm{~cm}^{-1}$ to $400 \mathrm{~cm}^{-1}$ at a spectral step of $2 \mathrm{~cm}^{-1}$. Resulted data were analyzed for each composite film using the Origin Software.

\subsection{Morphological studies}

The biocomposites surface morphology were scanned by SEM (Scanning Electron Microscope) (Inspect-S50, Ion/FEI company, US,) at a voltage of $10.00 \mathrm{kV}$. About $10 \mathrm{~nm}$ thickness of a gold layer of coated to all specimens before the observation process, conducted using sputter coater (SC7620 Emitech sputter coater, Quorum Technologies, UK).

\subsection{Thermogravimetric Analysis (TGA)}

The stability of the biocomposite to the thermal condition was analyzed by the TGA instrument (Perkin Elmer). The film of biocomposite grinded to form a powder material and put in the electric oven to dry it with a holding temperature of $80^{\circ} \mathrm{C}$ for two hours. $7 \mathrm{mg}$ biocomposite powder is put into a fire-resistant cup (porcelain) then analysis it in the TGA instrument. TG scanning was conducted under a heating rate of $10^{\circ} \mathrm{C} / \mathrm{min}$. until $1000^{\circ} \mathrm{C}$ with the airflow of $50 \mathrm{ml} / \mathrm{min}$.

\section{Result and Discussion}

\subsection{XRD Analysis}

The XRD analysis was conducted to observe the structure of the nanoclay-cassava starch/carrageenan composites. Diffractogram from XRD scanning of biocomposite with different nanoclay content was shown in Fig. 1. The XRD scanning results the diffractogram containing three diffraction peaks of biocomposite without nanoclay reinforcement was located in $2 \theta$ of $16.9^{\circ}, 19.6^{\circ}$ and $21.7^{\circ}$ which corresponds with a crystal plane of (103); (004); (220), respectively (Fig. 1). These peaks indicate that Bcrystal type of cassava, mainly contains the amylose, is the main content of the biocomposite matrix characterized by the diffraction peak at $17^{\circ} ; 22^{\circ}$, and $24^{\circ}$ [20]. The cassava peak matrix was shifted because of these bioplastics form the complexes of cassava-glycerol.

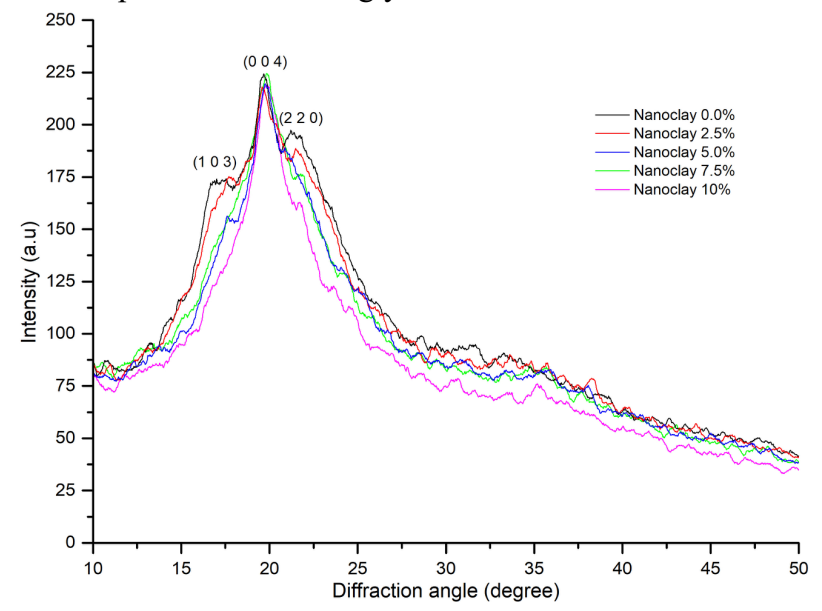

Fig. 1. XRD patterns of nanoclay reinforced biocomposite

The effect of nanoclay in the biocomposite was indicated through the reduction of peak intensity at peaks of $16.9^{\circ}$ and $21.7^{\circ}$. After the addition of nanoclay of $10 \%$, these peaks disappeared. Lossing of the pattern of the peaks indicates a partially or fully exfoliated in the biocomposite structure, causing by restriction to the movement of bioplastic molecules by nanoclay. During the composite synthesis, the amyloses have formed to the amylose-glycerol complexes, and the bioplastic polymer gets into the nanoclay galleries and split apart the nanoclay layers resulting in the uniform dispersion in the biocomposite matrix. The optimum interactions and compatibility between starch/carrageenan 
matrix and nanoclay at surface layer were vital to form of the exfoliated or intercalated starch/carrageenan-layered nanoclay composites [21].

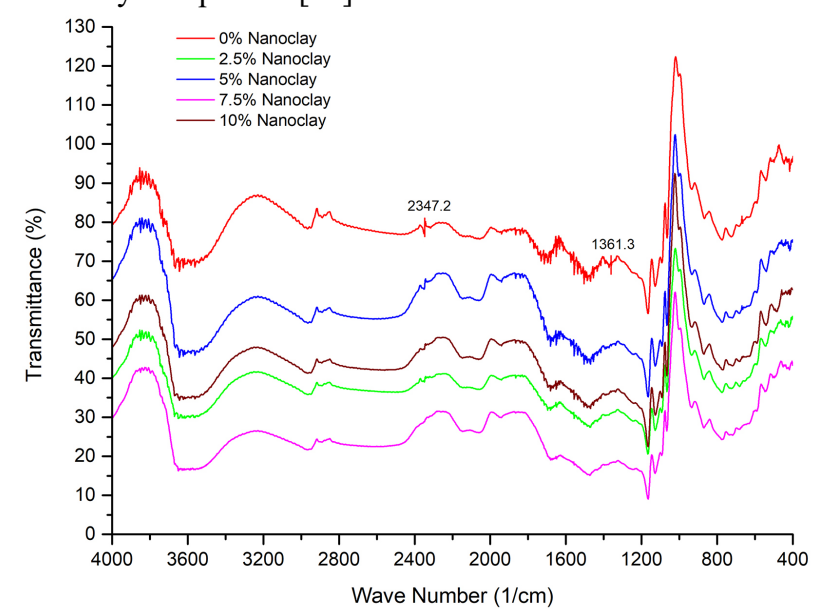

Fig. 2. FTIR spectra for nanoclay-reinforced biocomposite starch/carrageenan matrix

\subsection{FTIR Analysis}

The addition of nanoclay in the biocomposite change the chemical composition of biocomposite, and it can be analyzed using FTIR. The FTIR patterns of bioplastic were compared with nanoclay reinforced biocomposite, and it was shown in Fig. 2.

As shown in Fig 2, the broadband regions between the $3670-3000 \mathrm{~cm}^{-1}$ range were indicated the stretching of $\mathrm{OH}$ group in the starch as a biocomposite matrix [22]. The $\mathrm{O}-\mathrm{H}$ stretching observed in the biocomposite revealed the humid condition which might be due to the presence of bound or non-bound water molecules. The stretching of the $\mathrm{C}-\mathrm{H}$ group from alkanes (aliphatic compounds) in the range from 3000 to $2800 \mathrm{~cm}^{-1}$. There is no change in the $\mathrm{C}-\mathrm{H}$ group in bioplastic structure after addition of nanoclay. The intensity presence of this band decreased in biocomposite with a higher content of nanoclay, and disappear at nanoclay content of $5 \%$. This phenomenon indicates that nanoclay able to break the triple bond of the matrix to combine with nanoclay in the exfoliating mechanism. Peak around 2347 $2360 \mathrm{~cm}^{-1}$ is attributed to $\mathrm{CO}_{2}$ content resulting from measuring conditions and does not represent the bioplastic decomposition to $\mathrm{CO}_{2}$ [23]. The peaks at the wavenumber range from 1435 to $1405 \mathrm{~cm}^{-1}$ indicated the $\mathrm{C}-\mathrm{H}$ deformation and $\mathrm{CH}_{2}-$ bending vibrations. The strong absorption band in the wave number range of $1390-1360 \mathrm{~cm}^{-1}$ indicated $\mathrm{CH}_{3}$ symmetric bending with $\mathrm{CH} 3$ vibration, suggested the presence of acetates [24]. After the addition of nanoclay into biocomposite, peak 1361 was disappeared because the acetate was absorbed by nanoclay in the interlamellar space of the clay [25]. FTIR band in the 1200-800 regions gave information about the main polysaccharide present in complicated systems of polysaccharides mixture. The band in the region of 955-915 $\mathrm{cm}^{-1}$ suggested C-O-C out of plane stretching, a skeletal model of $\alpha$-glycosidic bond revealed the functional group of carboxylic acid and pyranose type sugars. A region associated with the skeletal model of amylose was found at 700 and $400 \mathrm{~cm}^{-1}$ [26].

\subsection{Mechanical Properties}

Results in the testing of the mechanical strength of biocomposite were shown in Fig. 3. The strength of biocomposite depends on the structure of the polymer and the role of blends and composites in manipulating properties
[27]. Addition of nanoclay to the biocomposite starch/carrageenan matrix increase biocomposite strength. The variations of nanoclay content in biocomposite of $0,2.5$, $5.0,7.5$, and $10 \%$ results in tensile strength of $580,636,760$, 483 , and $531 \mathrm{kPa}$ and elastic modulus of 1621, 1681, 1745, $1133,1176 \mathrm{kPa}$, respectively (Fig. 3). Nanoclay had changed the structures of biocomposite by way of formation of exfoliated silicate layer-based starch. The exfoliated morphologies in the biocomposite enhance the elastic properties until a concentration of 5\% [28].

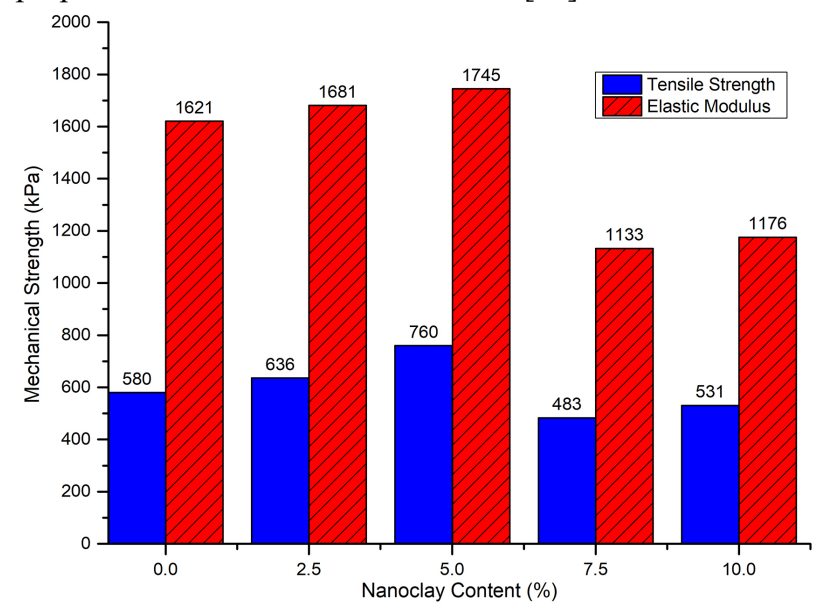

Fig.3. Mechanical properties of nanoclay-reinforced biocomposite starch/carrageenan matrix

The uniformity of nanoclay presence in the biocomposite structure results in higher density, compressive strength, and elastic modulus. The greater spacing of nanoclay gallery describes more molecules of starch diffused into space among the layers of silicate lead to increasing intensive reinforcement effects caused by higher interfacial interactions [29]. The good compatibility between nanoclay and the polymers results in improved mechanical properties, reduction of water absorption, the barrier to UV light, and stability in water which make very attractive biocomposite in their application.

\subsection{Morphology of fracture}

The morphology of the surface of biocomposite fractures the after tensile tests were shown in Fig. 4. After biocomposite is broken, the biocomposite based starch/carrageenan without nanoclay reinforcement shows a flat surface (Fig. $4 \mathrm{~A}$ ) then after reinforced by nanoclay $2.5 \%$, some agglomeration of nanoclay observed (Fig. 4B). Increasing concentration of nanoclay reinforcement in the biocomposite was made the surface rougher (Fig. 4C, Fig 4D).

In general, the bioplastics with nanoclay reinforcement showed insoluble particles on the fracture surface (Fig. 4, arrow mark), which associated with lower compatibility between nanoclay and a polymer matrix. By adding the nanoclay in the matrix, it can be related to the restricted mobility of the bioplastic chain in the interface region, in which polymer chains effectively interact to the nanoclay surface. After addition of the nanoclay by $5 \%$, the mechanical strength of the composite tends to decrease.

\subsection{Thermal Stability Analysis}

The stability in elevated temperature of the biocomposite was observed using a thermogravimetric analyzer (TGA). TGA was used to observe the reaction of thermal decomposition between weight loss due to the effect of temperature on the material [30]. In the thermal 
decomposition process, the material was changed into a simpler form that is influenced by many factors such as pressure, temperature, heating rate, moisture, particle size, residence time, and material composition.
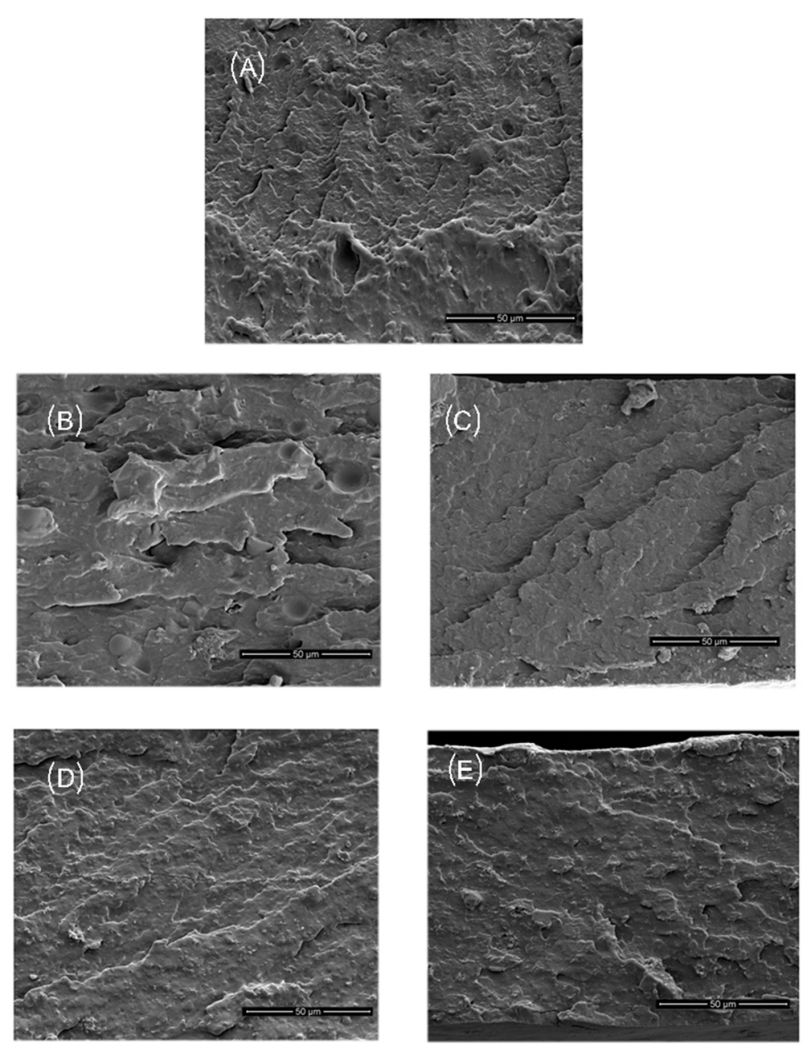

Fig. 4 Surface morphology of biocomposite starch/carrageenan matrix after tensile test: (A) Control (without nanoclay; nanoclay content of (B) $2.5 \%$, (C) $5.0 \%$, (D) $7.5 \%$, and (E) $10.0 \%$

The result of TGA testing is shown in Fig. 5. This curve shows the decomposition of biocomposite after subjected to heat. The decomposition is the process of a chemical reaction to the breakdown of organic material samples that release much heat. The biocomposite exhibited multi-step thermal decomposition process attributed to Stage I, II, III and IV which were observed at a temperature below $145^{\circ} \mathrm{C}$; at range $146-340{ }^{\circ} \mathrm{C} ; 341-475{ }^{\circ} \mathrm{C}$; and $476^{\circ}-1000^{\circ} \mathrm{C}$, respectively. Stage I represent the process of evaporation of water and devolatilization of glycerol used as a plasticizer. The weight loss in this stage was in the range from $7.3 \%$ to $8,7 \%$ (Table 1). Stage II represents the depolymerization process of the matrix with a high weight loss of sample (61$67.5 \%$ ). Amylose particles in cassava which can form carbohydrate lipids: oxygen, hydrogen, and carbon in the volatile cassava starch. Stage III was the process of transition of the char that indicate heterogeneity of polymer (about 21\% mass loss). In the 3rd stage, the composite changed to become charcoal. The charcoal is flammable as it is surrounded by volatile matter and oxygen diffused on the surface of the charcoal, which burns the charcoal and volatile matter simultaneously. This stage occurs after the release of volatile matter, which leaves or forms carbon [31]. Finally, after matrix degradation, the all sample decomposes to the ash as much as $2.2 \%, 2.2 \%, 4.1 \%, 5.8 \%$, and $9.9 \%$ for biocomposite without nanoclay reinforcement, with nanoclay content of $2.5 \%, 5.0 \%, 7.5 \%$, and $10 \%$, respectively (Stage IV). TGA results give an expression that the thermal stability of biocomposite enhanced after addition nanoclay reinforcement into biocomposite.

Table 1. Mass loss after thermal decomposition of biocomposite

\begin{tabular}{|c|c|c|c|c|}
\hline \multirow{2}{*}{$\begin{array}{c}\text { Nanoclay } \\
\text { content }(\%)\end{array}$} & \multicolumn{3}{|c|}{ Mass Loss (\%) } & \multirow{2}{*}{$\begin{array}{c}\begin{array}{c}\text { Ash Content } \\
(\%)\end{array} \\
\text { Stage } 4 \\
475^{\circ}-700^{\circ} \mathrm{C}\end{array}$} \\
\hline & $\begin{array}{c}\text { Stage } \\
1 \\
30^{\circ}- \\
145^{\circ} \mathrm{C}\end{array}$ & $\begin{array}{l}\text { Stage } \\
2 \\
145^{\circ}- \\
340^{\circ} \mathrm{C}\end{array}$ & $\begin{array}{c}\text { Stage } 3 \\
340^{\circ}- \\
475^{\circ} \mathrm{C}\end{array}$ & \\
\hline 0.0 & 8.7 & 67.6 & 21.5 & 2.2 \\
\hline 2.5 & 7.9 & 66.3 & 21.5 & 2.2 \\
\hline 5.0 & 7.8 & 65.6 & 22.5 & 4.1 \\
\hline 7.5 & 7.2 & 65.1 & 21.9 & 5.8 \\
\hline 10.0 & 7.3 & 61.0 & 21.8 & 9.9 \\
\hline
\end{tabular}

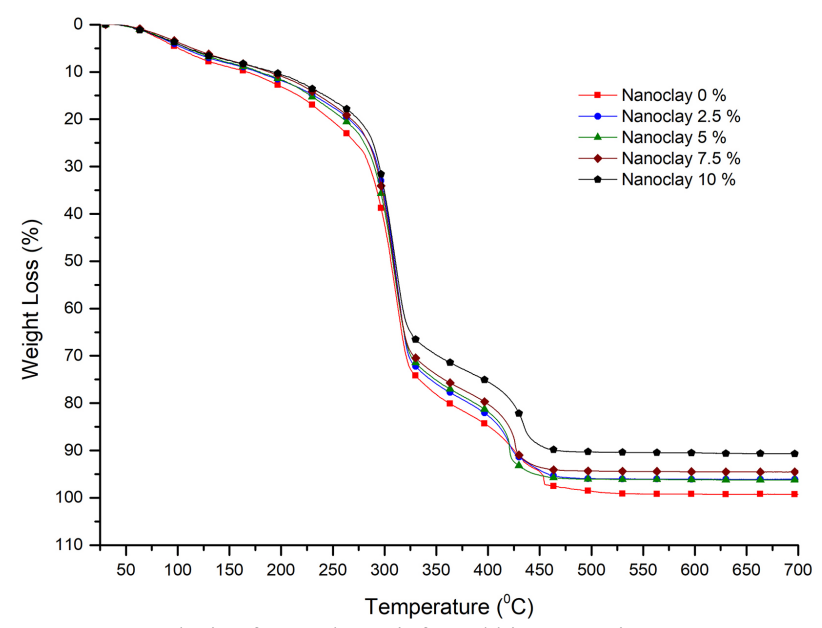

Fig. 5 TG Analysis of nanoclay-reinforced biocomposite starch/carrageenan matrix

\section{Conclusion}

The current work reports the effects of addition of nanoclay into starch/carrageenan matrix to increase the quality of biocomposite. The additional content of nanoclay in starch/carrageenan based biocomposite affects the tensile strength properties with an optimum at 5\% content of nanoclay. Biocomposite structure was change and more thermally stable after reinforced by nanoclay. These results suggest that the starch/carrageenan-based biocomposite with improved properties using nanoclay have a high potential application to enhance the properties of packaging materials.

\section{Acknowledgments}

Gratefully acknowledged to the Kemenristekdikti and LP2M Universitas Negeri Malang through the PDUPT Grant 2019.

This is an Open Access article distributed under the terms of the Creative Commons Attribution License

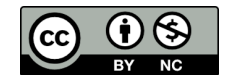




\section{References}

[1] B. R. Mose and S. M. Maranga, J. Mater. Sci. Eng. B. 1, 239 (2011).

[2] N. Rajendran, S. Puppala, S. M. Raj, and R. B. Angeeleena, J. Pharm. Res., 55, 1476 (2012).

[3] K. Kaiser, M. Schmid, and M. Schlummer, Recycling, 3, 1 (2018).

[4] K. S. Tumwesigye, J. C. Oliveira, and M. J. Sousa-Gallagher, Food Packag. Shelf Life, 7, 8 (2016).

[5] H. Webb, J. Arnott, R. Crawford, and E. Ivanova, Polymers, 5, 1 (2012).

[6] Statista, "Global plastic production," 2019. [Online]. Available: https://www.statista.com/statistics/282732/global-production-ofplastics-since-1950/.

[7] H. C. Chandara, Sunjoto, and Sarto, ASEAN J. Syst. Eng., 3, 65 (2016).

[8] A. M. Diez-Pascual, and A. L. Diez-Vicente, Int. J. Mol. Sci., 15, 10950 (2014).

[9] A. S. Abreu, M. Oliveira, de Sá, Arsenio, R. M. Rodrigues, M. A. Cerqueira, A. A. Vicente, and A. V. Machado, Carbohydr. Polym., 129, 127 (2015).

[10]H. P. S. A. Khalil, Y. Y. Tye, C. K. Saurabh, C. P. Leh, T. K. Lai, E. W. N. Chong, M. R. Nurul Fazita, J. Mohd Hafiidz, A. Banerjee, M. I. Syakir, Express Polym. Lett., 11, 244(2017).

[11] J. Necas and L. Bartosikova, Vet. Med., 58, 187 (2013).

[12] A. R. V Ferreira, V. D. Alves, and I. M. Coelhoso, Membranes, 6, 1 (2016).

[13]J. Muller, C. González-Martínez, and A. Chiralt, Materials, 10, 952 (2017).

[14]D. Jagadeesh, K. Prashantha, N. Mithil Kumar Nayunigari, and A. Maity, Indian J. Adv. Chem. Sci., 4, 355 (2016).

[15] A. Lopez-Gil, M. A. Rodriguez-Perez, J. A. De Saja, F. S. Bellucci, and M. Ardanuy, Polimeros, 24, 36 (2014).

[16] A. Fadeyibi, Z. D. Osunde, E. C. Egwim, and P. A. Idah, J. Agric. Eng., 48, 137 (2017).
[17]N. Akter, R.A. Khan, M. O. Tuhin, M. E. Haque, M. Nurnabi, F. Parvin, R. Islam, J. Thermoplast. Compos. Mater., 27, 933 (2014).

[18]H. Suryanto, P. T. Hutomo, R. Wanjaya, and P. Puspitasari, AIP Int. Proceeding Int. Mech. Eng. Eng. Educ., Malang, Indonesia, 30027, pp. 1-5 (2016).

[19]H. Suryanto, S. Jenuardy, D. Kustono, P. Puspitasari, and D. Z. Lubis, Int. Rev. Mech. Eng., 12, 272 (2018).

[20]N. A. Aviara, J. C. Igbeka, and L. Nwokocha, Int. agrophysics., 24, 219 (2010).

[21]X. Tang, S. Alavi, and T. J. Herald, Cereal Chem., 85, 433 (2008).

[22]C.-H. Tsou, M.-C. Suen, W.-H. Yao, J.-T. Yeh, C.-S. Wu, C.-Y. Tsou, S.-H. Chiu, J.-C. Chen, R. Y. Wang, S.-M. Lin, W.-S. Hung, M. De Guzman, C.-C. Hu and K.-R. Lee, Materials, 7, 5617 (2014).

[23] M. M. Altayan, T. Al Darouich, and F. Karabet, Food Biophys., 12, 397 (2017).

[24]A. R. Uribe, Fundamental and Characterization of Fungally Modified Polysaccharides for the Production of Bio-Plastics, University of Toronto, p. 39. (2010).

[25] X.-C. Wang and C. Lee, Mar. Chem., 44, 1 (1993).

[26]M. Deepa, Characterization of Native and Nano Sorghum Starch and Its Application as an Edible Coating Base, Dissertation, Periyar University, 2015.

[27]E. S. Stevens and M. D. Poliks, J. Chem. Educ., 80, 810 (2003).

[28] J. L. Suter, D. Groen, and P. V. Coveney, Nano Lett., 15, 8108 (2015).

[29]C. M. O. Müller, J. B. Laurindo, and F. Yamashita, Carbohydr. Polym., 89, 504 (2012).

[30]Y. Zhaosheng, Xiaoqian Ma, and L. Ao, Biomass and Bioenergy, 32, 1046 (2008).

[31]V. M. Azevedo, M. V Dias, S. V Borges, A. Letícia, R. Costa, and E. Keven, Food Hydrocoll., 48, 179 (2015). 